\title{
Modelagem Tridimensional Digital em Abordagem \\ Tectônica na Concepção da Arquitetura
}

Digital Three-dimensional Modeling by a tectonic approach in architectural design

\author{
> Germana Costa Rocha \\ Universidade Federal da Paraíba, Brasil \\ germanarocha@ct.ufpb.br
}

\author{
> Aristóteles L. M. Cordeiro \\ Universidade Federal da Paraíba, Brasil \\ aristotelescordeiro@gmail.com
}

\begin{abstract}
This paper reports a teaching and learning experience of architectural digital three-dimensional geometric modeling from its tectonic character, with regard to the interactions between the formal architectural framework and its sturdy structure. Was held at the undergraduate course in Architecture and Urbanism of the Universidade Federal da Paraíba. It's an interdisciplinary exercise aimed at the integration of knowledge where students utilize the contents learned in the discipline of Structural Systems I for the construction of a digital three-dimensional geometric model with the Trimble's software Sketchup in the Perspective discipline, resulting in the development of models with greater formal consistency.
\end{abstract}

Keywords: Digital modeling; Structural systems; Architectural education

\section{Introdução}

Em arquitetura, a modelagem geométrica tridimensional através de ferramentas digitais, tem assumido relevante papel na dialogia que se estabelece no processo projetual. Os recentes avanços de programas computacionais com interface e comandos que facilitam a modelagem tridimensional, no que diz respeito às instancias de visualização, edição, animação e texturização, vêm estendendo a participação destas ferramentas no processo de projeto desde a fase de concepção ao detalhamento executivo. Os programas de modelagem tridimensional são, cada vez mais, instrumentos fundamentais à concepção arquitetônica desde as primeiras instâncias da formação do arquiteto e urbanista.

Embora as ferramentas de modelagem geométrica tridimensional digital facilitem a criação da forma desde as mais simples às mais complexas, a concepção da forma arquitetônica não prescinde dos saberes construtivos, uma vez que a tensão entre estrutura física e estrutura visual constitui um dos problemas centrais da criação arquitetônica, e "abstrair-se da realidade física da arquitetura significa cair na pura geometria”, conforme bem argumenta Mahfuz (2003, p. 69).

A proposta deste trabalho é apresentar uma experiência de ensino-aprendizagem de modelagem geométrica tridimensional digital da arquitetura a partir de seu caráter tectônico, no que diz respeito às interaçóes entre a estrutura formal arquitetônica e sua estrutura resistente.

Para muitos estudiosos como Angus MacDonald (2001), Lopes (2006) e Rebello (2000), a estrutura formal arquitetônica necessita nascer concomitantemente a uma proposta de estrutura resistente, que lhe é intrínseca, para que a primeira não corra o risco da não exequibilidade, principalmente quando ela define a própria arquitetura. Ou seja, quando os requisitos da estrutura resistente aparecem como elementos significantes de sua linguagem e expressividade.

Trata-se de um exercício interdisciplinar visando a integração de saberes, em que os alunos utilizam o conteúdo apreendido na disciplina Sistemas Estruturais I, em semestre anterior, para fundamentar a construção de modelo geométrico tridimensional digital na disciplina Perspectiva, dois períodos depois, que utiliza o Programa Sketchup da Trimble.

Estando as duas disciplinas em períodos iniciais em um curso de Arquitetura e Urbanismo, a interdisciplinaridade visa colaborar para o desenvolvimento de uma consciência construtiva desde os primeiros anos da formação do arquiteto, estimulando a concepção da estrutura resistente da forma arquitetônica desde as primeiras fases do processo projetual. O que pode ser alcançado com maior facilidade através dos recursos das ferramentas digitais utilizadas para a construção de modelos geométricos tridimensionais.

\section{A Interdisciplinaridade}

A disciplina Sistemas Estruturais I, ministrada no primeiro período do curso de Arquitetura e Urbanismo da Universidade Federal da Paraíba - UFPB, tem como objetivos fundamentar a identificação e compreensão qualitativa dos fenômenos estruturais básicos de edifícios e estimular a concepçáo estrutural no processo de criação do espaço arquitetônico a partir da apreensão da relação entre estrutura resistente e estrutura arquitetônica. 
Os dois primeiros módulos dessa disciplina são fundamentalmente teórico-analíticos, sendo o terceiro de ordem teórico-prática, em que os alunos aplicam e experimentam os conceitos e fundamentos das associaçóes de sistemas estruturais básicos para a concepção da cobertura de um espaço arquitetônico, representado a partir de modelos físicos reduzidos - maquetes - (Fig. 01), sendo utilizados para pré-dimensionamento dos sistemas estruturais os gráficos contidos em Rebello (2000), elaborados pelo professor Philip A. Corkill da Universidade de Nebraska e traduzidos e adaptados para o sistema métrico decimal pelo professor Yopanan Rebello e Walter Luiz Junc.
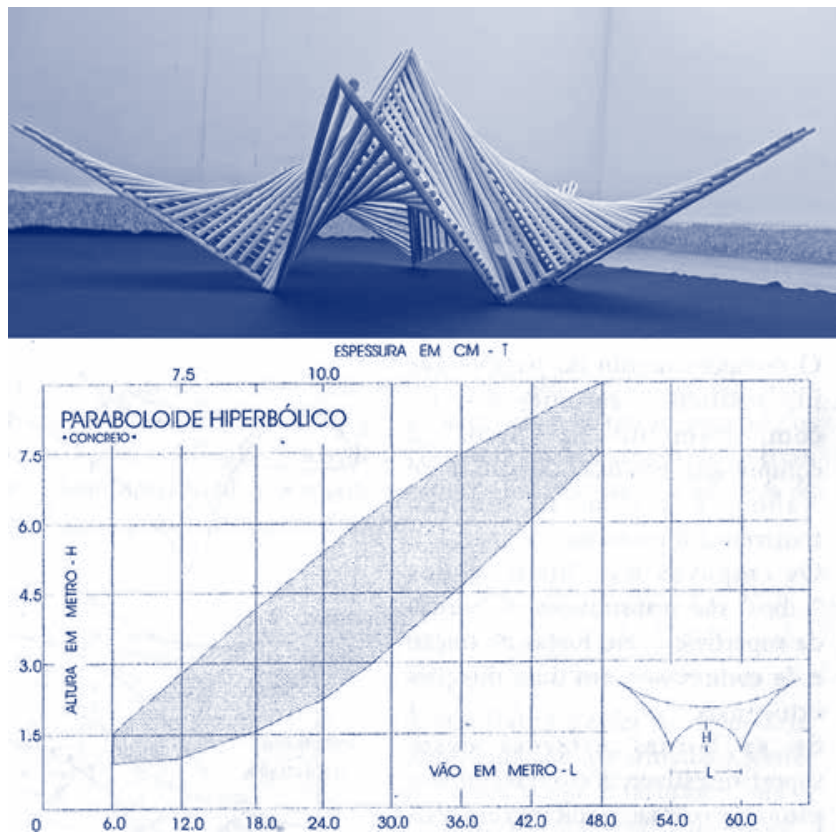

Figura 01: Estrutura em paraboloide hiperbólico. Modelo físico reduzido executado pelas alunas Alessandra Santos Lima da Cunha e Natália dos Santos Linhares, em 2014 (acima) e gráfico utilizado para o pré-dimensionamento (abaixo) extraído de Rebello (2000).

A disciplina Perspectiva tem como objetivos capacitar operacionalmente o aluno a construir modelos geométricos tridimensionais virtuais representando edificaçôes e seus entornos, a utilizar os modelos como ferramenta para a concepção e avaliaçáo do projeto arquitetônico e para a simulação de desempenho do edifício, além de promover o uso de perspectivas como recurso de comunicaçáo em projeto.

Sendo uma das disciplinas da matéria Informática aplicada à Arquitetura e Urbanismo, ao longo do último decênio, e acompanhando a difusão de ferramentas digitais de apoio ao projeto arquitetônico, fez uso inicialmente do programa AutoCAD, depois do programa AutoCAD associado ao programa ARCAD, aplicativo para a modelagem $3 \mathrm{D}$ de edifícios e, nos últimos quatro anos tem utilizado o programa Sketchup e o Layout. O primeiro para a modelagem 3D e o segundo para a representação do modelo em folhas ou pranchas. Como vem sendo realizado há alguns anos, ao final de cada período letivo, o aluno deve construir um modelo tridimensional de um objeto arquitetônico com base em um tema dado, para que demonstrem a habilidade de utilização dos recursos oferecidos pela ferramenta. Em um dos períodos passados o exercício de modelagem consistiu em propor uma passarela de pedestres sobre um pequeno rio unindo dois bairros em João Pessoa - PB (Fig. 02).

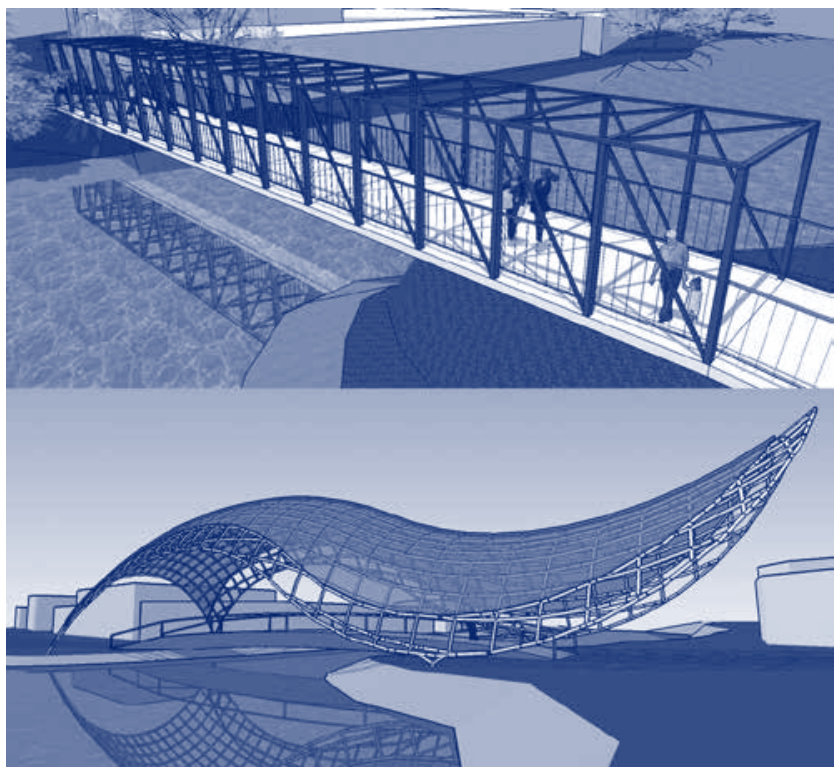

Figura 02: Estrutura em treliça metálica plana elaborada pela aluna Lisandra Rafaela de Souza (acima), e estrutura em associação de arco e treliça plana elaborada pelo aluno André Siqueira Souto Melo (abaixo) na disciplina Perspectiva em 2013.

Ministrando aulas nessas duas disciplinas, e também nas disciplinas de projeto de edificaçóes, em semestres mais avançados do curso, observamos que o conteúdo apreendido na disciplina Sistemas Estruturais I - localizada no primeiro semestre do curso - não vinha sendo aplicado pelos alunos, nas disciplinas propositivas dos semestres seguintes, sendo um dos motivos, alegado por eles próprios, a dificuldade de representar graficamente alguns sistemas estruturais de formas arquitetônicas mais complexas. Por outro lado, observou-se, igualmente, que vários modelos digitais elaborados pelos alunos no exercício final da disciplina Perspectiva, apresentavam distorçóes do ponto de vista da escala e proporção dos elementos compositivos da forma, em particular, os elementos da estrutura resistente. Esta constatação foi o que nos motivou a realizar uma ação de interdisciplinaridade, entre Sistemas Estruturais I e Perspectiva (localizadas no primeiro e terceiro período do curso, respectivamente) como maneira estimular os discentes a fazer a síntese entre concepção estrutural e a concepção arquitetônica no processo de projeto, mas, também, em colaborar na obtenção de uma visão integral do curso e da arquitetura, incentivando-os a recompor, como estratégia didática, os saberes adquiridos de forma fragmentada nas diversas disciplinas.

\section{Caminhos e resultados}

$\mathrm{Na}$ experiência em apreço, o objeto de modelagem se constituiu em uma edificaçáo em que a estrutura formal arquitetônica fosse 
definida pela sua estrutura resistente, conforme a classificação de Macdonald (2001), structure as architecture (estrutura como arquitetura), para que se evidencie o fundamento do exercício que consiste na proposição de espaço arquitetônico a partir das interaçóes entre estrutura formal e estrutura resistente, numa abordagem tectônica de concepção da arquitetura.

A metodologia adotada fundamentou-se no conteúdo das duas disciplinas, seguindo as etapas do quarto exercício da disciplina Sistemas Estruturais I, mudando o objeto final, ou seja, substituindo o modelo físico reduzido pelo modelo geométrico tridimensional digital de uma estrutura formal arquitetônica.

O primeiro passo do exercício consistiu na escolha, pelos alunos, de um sistema ou associação de sistemas estruturais - arco, treliça, viga vierendeel, viga de alma cheia e cabo, arco e treliça, ou membrana tensionada - como classificado em Yopanan Rebello (2000) e estudados, anteriormente, na disciplina Sistemas Estruturais I. Em seguida, realizou-se uma pesquisa bibliográfica de obras arquitetônicas significativas e que utilizam o sistema resistente selecionado para que uma delas servisse de base à proposição de uma estrutura formal arquitetônica, com função definida pelo aluno e formalizada através da construçấo de um modelo geométrico tridimensional digital.

A modelagem da estrutura resistente, à maneira do exercício realizado na disciplina Sistemas Estruturais I, foi precedida do prédimensionamento utilizando-se dos gráficos contidos em Rebello (2000), aonde as dimensóes dos elementos estruturais são estimadas para diferentes tamanhos de vãos. Por último, o modelo do objeto arquitetônico deveria ser inserido em um entorno paisagístico, natural ou urbano, igualmente concebido e modelado pelo aluno a partir da ferramenta digital (Fig. 01 e 02).

Foi estabelecido como resultado da tarefa a apresentação e entrega de um arquivo do Sketchup contendo o modelo digital tridimensional com mais de uma cena a partir de diferentes posiçóes e alturas do observador, e outro arquivo no formato PDF contendo uma imagem da obra pesquisada com referências de local e autoria, assim como uma imagem do modelo elaborado em 3D.

Foram adotados e apresentados antecipadamente aos alunos os seguintes critérios de avaliação para o trabalho: a semelhança com o modelo original, no que diz respeito ao sistema estrutural; a qualidade das cenas; a organização e a estrutura do modelo; a modelagem do contexto e entorno; a aplicação de materiais de acabamento e a qualidade da apresentação em PDF.

A experiência do exercício final da disciplina Perspectiva - a construção de um modelo tridimensional digital, com base em uma obra arquitetônica existente - tem mostrado que durante o processo de modelagem do objeto escolhido os alunos avançam no conhecimento da ferramenta, uma vez que eles próprios buscam ou "descobrem" novos caminhos ou comandos dentro do programa, que facilitam a modelagem e os modos de visualizaçáo que eles querem alcançar. (Fig. 03 e 04).

\section{À Guisa de Discussão}

A construção de modelos $3 \mathrm{D}$ gerados através de ferramentas informatizadas de auxílio ao projeto e fundamentados no caráter tectônico da arquitetura, revelou-se um excelente instrumento didático do saber-fazer arquitetônico. Isto porque este processo

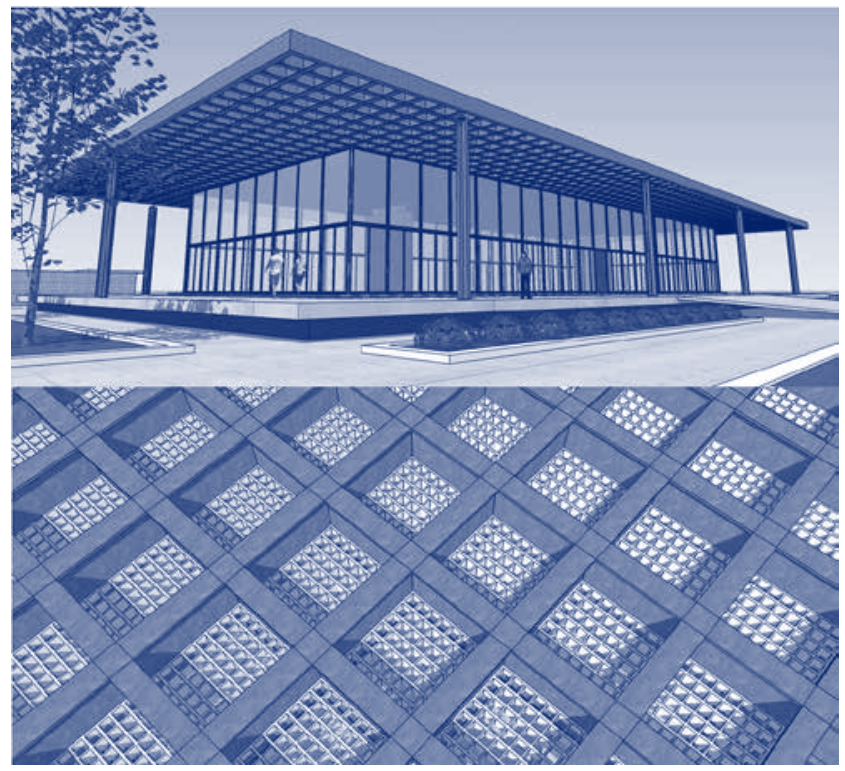

Figura 03: Estrutura em grelha. Obra original: The New National Gallery, Berlin, Arquiteto Mies van der Rohe. Modelo digital elaborado pelo aluno Renan Pinheiro da Costa Medeiros, em 2014.

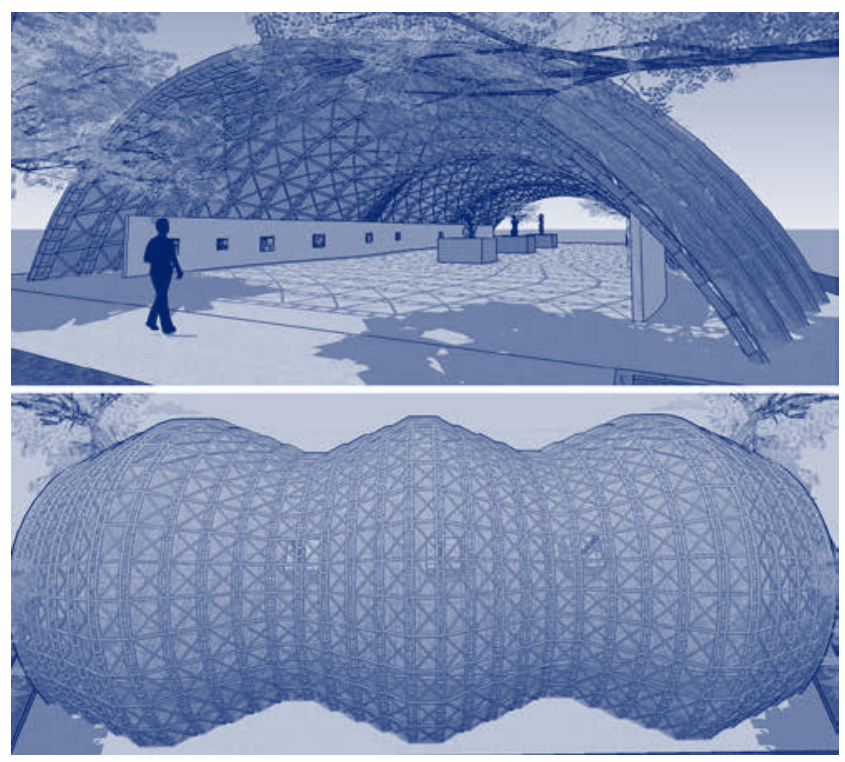

Figura 04: Estrutura em associação de arco e treliça. Obra original: Pavilhão do Japão (EXPO 2000), Hannover, Arquiteto Shigeru Ban. Modelo digital construído pela aluna Maria Alice pontes de Carvalho, em 2014.

evidencia a integração entre as partes da estrutura resistente e os elementos formais e espaciais da arquitetura.

Para tanto, torna-se necessário construir um modelo 3D isomórfico, unívoco e relacional, que reproduza vis-à-vis as suas partes e componentes e, que tenham relaçóes lógicas de dependência entre estas partes (CORDEIRO, 2007).

Os métodos e as técnicas para a modelagem tridimensional na disciplina Perspectiva buscam a construçáo de modelos das 


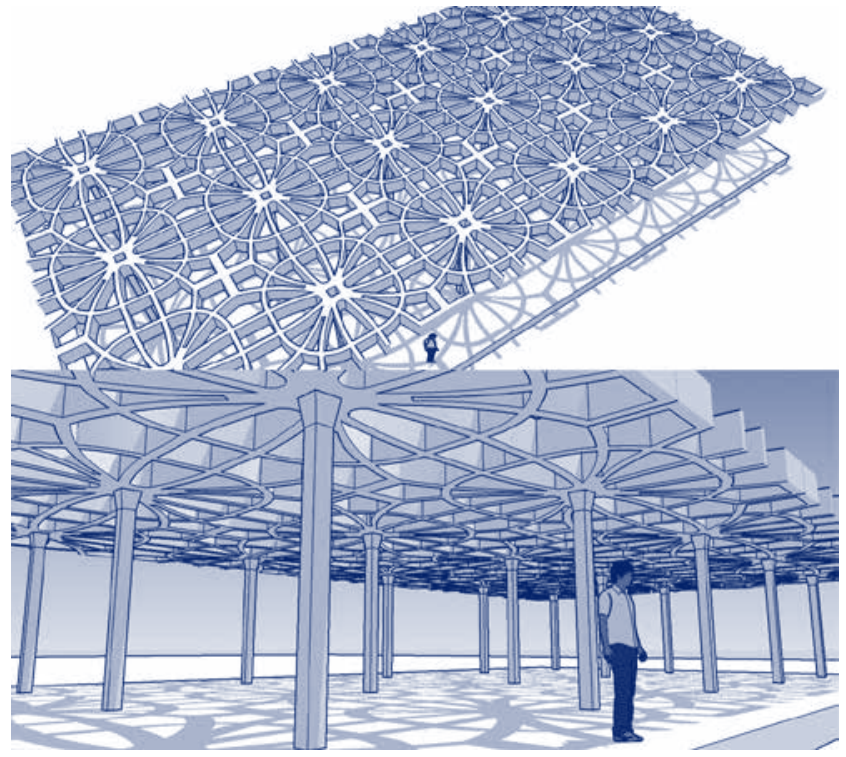

Figura 05: Estrutura em grelha. Obra original: Fábrica Bacardi de Félix Candela. Modelo digital construído pelo aluno Adalberto Duarte Santos Junior, em 2014.

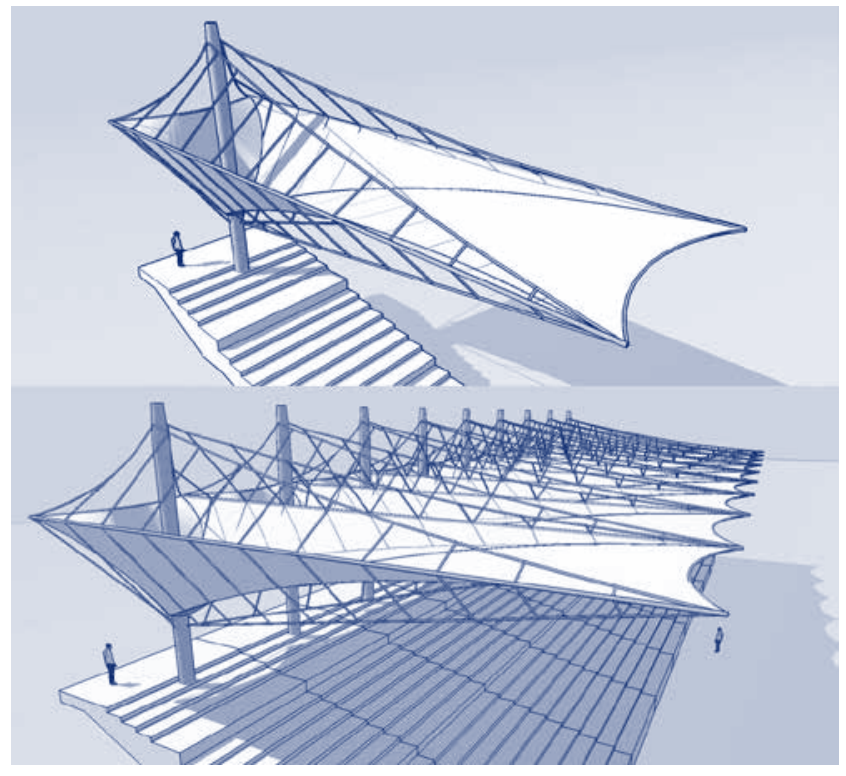

Figura Ø6: Estrutura tensionada com cabos - obra original: Oldenburg Grandstand de Schlaich Bergernann. Modelo digital construído pelo aluno Adson Edson de Silva Diniz, em 2014.

edificaçóes e seus entornos de forma a que estas três características estejam sempre presentes. São elas que possibilitam a construção de modelos multifuncionais e integrados ao ambiente donde se dá a síntese arquitetônica.

O isomorfismo é a característica que impóe, de antemão, a tridimensionalidade dos modelos. Se o isomorfismo determina que o modelo deva ser formalmente semelhante ao objeto edificado, temos por corolário, que só um modelo tridimensional é capaz de atender adequadamente a esta característica.
A utilização da expressão "formalmente semelhante" deriva da impossibilidade teórica - e prática - de se construir um modelo que tenha vinculações formais de identidade com o objeto, em outras palavras, que lhe seja formalmente idêntico. Assim é necessário estabelecer à priori qual o grau de similaridade da representação formal tendo em vista as funçóes que modelo deve exercer ao longo do ciclo de projeto.

Para os objetivos do exercício semestral, o isomorfismo entre o modelo e o objeto estava restrito aos aspectos geométricos e de posicionamento assim como a aplicaçáo dos materiais de acabamento.

A segunda característica buscada nos modelos construídos na disciplina de Perspectiva é de serem unívocos. Esta característica implica em uma relação vis-à-vis entre o modelo e o objeto, significando estritamente que cada parte ou componente do objeto será representado no modelo por apenas uma única entidade gráfica, no caso um sólido tridimensional.

A técnica para atender a esta característica no Sketchup consiste em agrupar o conjunto das superfícies que constituem a envoltória de um sólido em um único componente nomeado de tal forma que identifique facilmente a parte representada. Os componentes sólidos podem ser agrupados em conjuntos maiores reproduzindo a hierarquia de sistemas construtivos.

A utilização desta estratégia de modelagem já avança na direção a satisfação da terceira característica dos modelos, a de serem relacionais. Um modelo unívoco e isomórfico, sem que as suas partes estejam relacionadas em um esquema lógico, é apenas uma coleção de entidades gráficas e está longe de representar, no caso de modelos arquitetônicos, uma edificação, se a tomamos como um sistema complexo onde os subsistemas e partes que a compóem tem mais do que relaçóes topológicas entre si.

A aferiçáo de grau em que as partes e os componentes de um modelo se relacionam entre si, no programa Sketchup, é efetivada observando-se qual a estrutura adotada para o modelo, ou seja, como foram estabelecidas as suas partes - os sólidos - e como eles se relacionam ou estabelecem relaçóes de hierarquia entre si.

Esta operação lógica, a de decompor a edificação ou sistema construtivo real que serve de objeto em suas partes constituintes não visa apenas a garantir o caráter unívoco e relacional do modelo digital. Demanda o desenvolvimento de um olhar analítico onde os conhecimentos sobre as estruturas resistentes vão conduzir a decomposição formal do objeto, uma forma profissional de ver a edificação. Uma das mais importantes contribuiçóes na utilização de modelos tridimensionais digitais no curso de arquitetura e a facilidade em que eles possibilitam o desenvolvimento deste olhar analítico.

\section{Considerações Finais}

A experiência ora relatada, não pretende encerrar toda a problemática existente na apreensão de saberes em curso de arquitetura, a partir do método e exercício adotado. Apenas contribuir para reflexão sobre o uso de ferramentas digitais na apreensão e concepçáo da forma arquitetônica desde o início da formação do arquiteto e urbanista.

A realização deste exercício interdisciplinar, além de promover a recapitulação e a consolidação dos conhecimentos apreendidos em um período anterior, no caso da disciplina Sistemas Estruturais I, 
igualmente promoveu a construção de modelos digitais com uma maior consistência formal, ao considerar o caráter tectônico da arquitetura. Estes modelos digitais por sua vez passam a se constituir em ferramentas de auxílio didático para a disciplina Sistemas Estruturais realimentando o processo de interdisciplinaridade.

Acredita-se que experiências similares estejam acontecendo nos cursos de arquitetura e urbanismo, decorrentes da difusão e do aperfeiçoamento das ferramentas digitais de modelagem tridimensional. A mudança de paradigma que estas ferramentas proporcionam, a passagem de uma concepçáo de projetos baseada em desenhos para uma concepção de projetos baseadas em modelos é um estímulo para experimentar novas formas e técnicas de conduzir o ensino e a aprendizagem na arquitetura.

\section{Referências}

Cordeiro, A. L. de M. (2007) O projeto de edifícios em ambientes informatizados: Uma abordagem macroergonômica. Tese de Doutorado. João Pessoa, PPGEU/UFPB.

Chupin, J-P \& Simonnet, C. (2005). Le projet tectonique - introduction de Kenneth Frampton. Collection Archigraphy Les Grands Ateliers, Infolio éditions.
Frampton, K (1995). Studies in tectonic culture. 2ed. Massachusetts: Mit Press.

Lopes, J. M.(2006). Arquiteturas da engenharia ou engenharias da arquitetura. São Paulo: Mandarim.

Macdonald, A. J. (2001) Structure and Architecture. Departament of Architecture, University of Edinburgh. Second Edition. Architectural Press.

Mahfuz, Edson da Cunha (2003). Reflexôes sobre a construção da forma pertinente. In. F. Lara \& S. Marques. Projetar - Desafios e conquistas da pesquisa e do ensino. Rio de Janeiro: Editora Virtual Científica.

Oliveira, M. B. (2010). Google Sketchup Pro aplicado ao projeto arquitetônico. São Paulo, Novatec Editora.

Piñón, Hélio. (2006). Teoria do Projeto. Traduzido por Edson Mahfuz. - Porto Alegre: Livraria do Arquiteto.

Rebello, Y. (2000). A concepção estrutural e a arquitetura. São Paulo: Zigurate, 2000.

Tal, D. (2009). Google Sketchup for site design: a guide to modeling site plans, terrain and architecture. New Jersey, John Wiley \& Sons. 